Article

\title{
Application of the Hybrid Simulation Method for the Full-Scale Precast Reinforced Concrete Shear Wall Structure
}

\author{
Zaixian Chen ${ }^{1, *}$, Huanding Wang ${ }^{1,2}$, Hao Wang ${ }^{3}{ }^{(0)}$, Hongbin Jiang ${ }^{2}$, Xingji Zhu ${ }^{1, *}$ and \\ Kun Wang ${ }^{4}$ \\ 1 Department of Civil Engineering, Harbin Institute of Technology at Weihai, Weihai 264209, China; \\ hdwhrb@hit.edu.cn \\ 2 Harbin Institute of Technology, School of Civil Engineering, Harbin 150090, China; 86282081@163.com \\ 3 Department of Civil Engineering, Southeast University, Nanjing 210096, China; wanghao1980@seu.edu.cn \\ 4 College of Civil Science and Engineering, Yangzhou University, Yangzhou 225127, China; \\ wangkun@yzu.edu.cn \\ * Correspondence: zaixian_chen@sina.com (Z.C.); zhuxingji@hit.edu.cn (X.Z.); Tel.: +86-0631-568-7845 (Z.C.)
}

Received: 2 January 2018; Accepted: 1 February 2018; Published: 7 February 2018

\begin{abstract}
The hybrid simulation (HS) testing method combines physical test and numerical simulation, and provides a viable alternative to evaluate the structural seismic performance. Most studies focused on the accuracy, stability and reliability of the HS method in the small-scale tests. It is a challenge to evaluate the seismic performance of a twelve-story pre-cast reinforced concrete shear-wall structure using this HS method which takes the full-scale bottom three-story structural model as the physical substructure and the elastic non-linear model as the numerical substructure. This paper employs an equivalent force control (EFC) method with implicit integration algorithm to deal with the numerical integration of the equation of motion (EOM) and the control of the loading device. Because of the arrangement of the test model, an elastic non-linear numerical model is used to simulate the numerical substructure. And non-subdivision strategy for the displacement inflection point of numerical substructure is used to easily realize the simulation of the numerical substructure and thus reduce the measured error. The parameters of the EFC method are calculated basing on analytical and numerical studies and used to the actual full-scale HS test. Finally, the accuracy and feasibility of the EFC-based HS method is verified experimentally through the substructure HS tests of the pre-cast reinforced concrete shear-wall structure model. And the testing results of the descending stage can be conveniently obtained from the EFC-based HS method.
\end{abstract}

Keywords: equivalent force control; hybrid simulation; full-scale; nonlinear seismic performance; descent stage

\section{Introduction}

The seismic testing method is an important way to evaluate the structure nonlinear seismic performance and verify the feasibility of the structure seismic theory. The hybrid simulation (HS) testing method, which is named initially as the pseudo-dynamic substructure testing method, was proposed in 1969 [1]. This method combines the physical test of the critical nonlinear parts of a structure and the numerical simulation of the remainder. It can effectively reduce the size of the test model and is an efficient and versatile testing tool for the large-scale structural model.

The novel technique of the HS method, which mainly includes (1) the robust numerical integration techniques [2-7]; (2) the loading control method [8-14]; (3) the geographically distributed HS [15-20]; and (4) the parameter identification of HS [21-26] for the implement and improvement of HS method. 
Especially, the real-time HS plays a powerful role to evaluate the rate dependent behaviors, such as magneto-rheological damper or vibration isolation system [18,27-36]. Additionally, the Network for Earthquake Engineering Simulation (NEES), which featured 14 geographically distributed and shared-use laboratories to test modern structural system [37-40], accelerates the development of the HS platforms (OpenFresco manufactured by dSpace, and MTS (STS and FlexTest systems) National Instru ments [41], and UI-Simcor developed by the MUST-SIM facility and the MAE Center at the University of Illinois at Urbana-Champaign [42]). It was widely used to realize the performance assessment of modern building structure systems conveniently.

Although HS method has been advanced continuously in the last four decades, previous studies mainly focused on the accuracy, stability and reliability. And only the small-scale tests were used to examine the feasibility of the HS method [43,44]. A few large-scale structural testing models were examined by the HS method $[24,31,45,46]$. To accelerate the development of the HS method in the large-scale model, a full-scale three-story precast reinforced concrete shear-wall substructure model is built as the physical substructure to evaluate the seismic performance of the entire twelve-story structure, in this paper.

Note that there are two challenges associated with the implementation of the controller for this full-scale HS method, including: (1) the complex test setup which employed four electro-hydraulic servo actuators as the horizontal loading device; and (2) the complex structural model which is asymmetric due to the asymmetric structural arrangement of the model. In order to solve the above two problems, an equivalent force control (EFC) method with implicit integration algorithm is proposed to deal with the numerical integration of the equation of motion (EOM) and the control of the loading device. The general arrangement of the whole test which includes the test model, the loading device and the testing device are all described. Following that, a discussion of the EFC method for the test model is presented. Then, the parameters for the EFC-based HS method are determined by the numerical simulation. Finally, an experimental validation is carried out to demonstrate the efficacy of the proposed approach.

\section{Test Arrangement}

\subsection{Test Model}

The twelve-story pre-cast reinforced concrete shear wall structure was designed based on both the Chinese Code GB50010 for Design of Concrete Structures and the Chinese Code for Seismic Building Design GB50011. The seismic precautionary intensity of the region is 7 degrees for the structural model. As shown in Figure 1, the plan dimension of the test model is $4200 \mathrm{~mm} \times 3000 \mathrm{~mm}$. And the height of each story is $3000 \mathrm{~mm}$. The thickness of the shear wall is $200 \mathrm{~mm}$. The cross-section of the coupling beam connected to the walls is $200 \mathrm{~mm} \times 400 \mathrm{~mm}$. The design value of the concrete compression strength for the test model is $30 \mathrm{MPa}$. The HRB335 steel is employed for the reinforcements of the beams and the HPB235 for the stirrups and slab. Because of the limitations of the test site and loading device, a full-scale three-story precast concrete shear wall substructure model was built as the physical substructure in the Structural and Seismic Testing Center of Harbin Institute of Technology, as shown in Figure 2. A foundation beam, which is $600 \mathrm{~mm}$ high, was constructed to ensure the fixed connection with the laboratory floor. Therefore, the total height of the physical substructure model is $9600 \mathrm{~mm}$.

From Figures 1 and 2, the tension stiffness of the model is not equal with the compression stiffness due to the arrangement of the door and window in the plan. Table 1 shows the inter-story stiffness of the test model. Note that the initial stiffness in positive and negative direction is calculated by the measured drift and shear force at different floors of the physical substructure, which are obtained by loading at the top of the physical substructure. Because of the same structural layouts from the second floor to the sixth floor, here an average value of the stiffness between the second and third floor can be considered as the initial stiffness for over the second floor. The details of material properties are shown in Tables 2 and 3. 


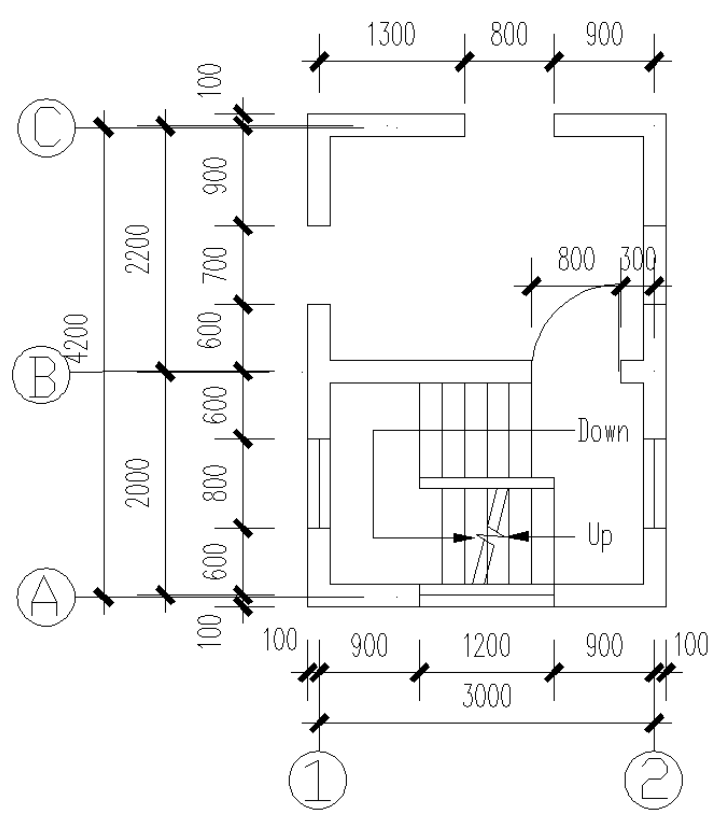

Figure 1. Plan of the test model.

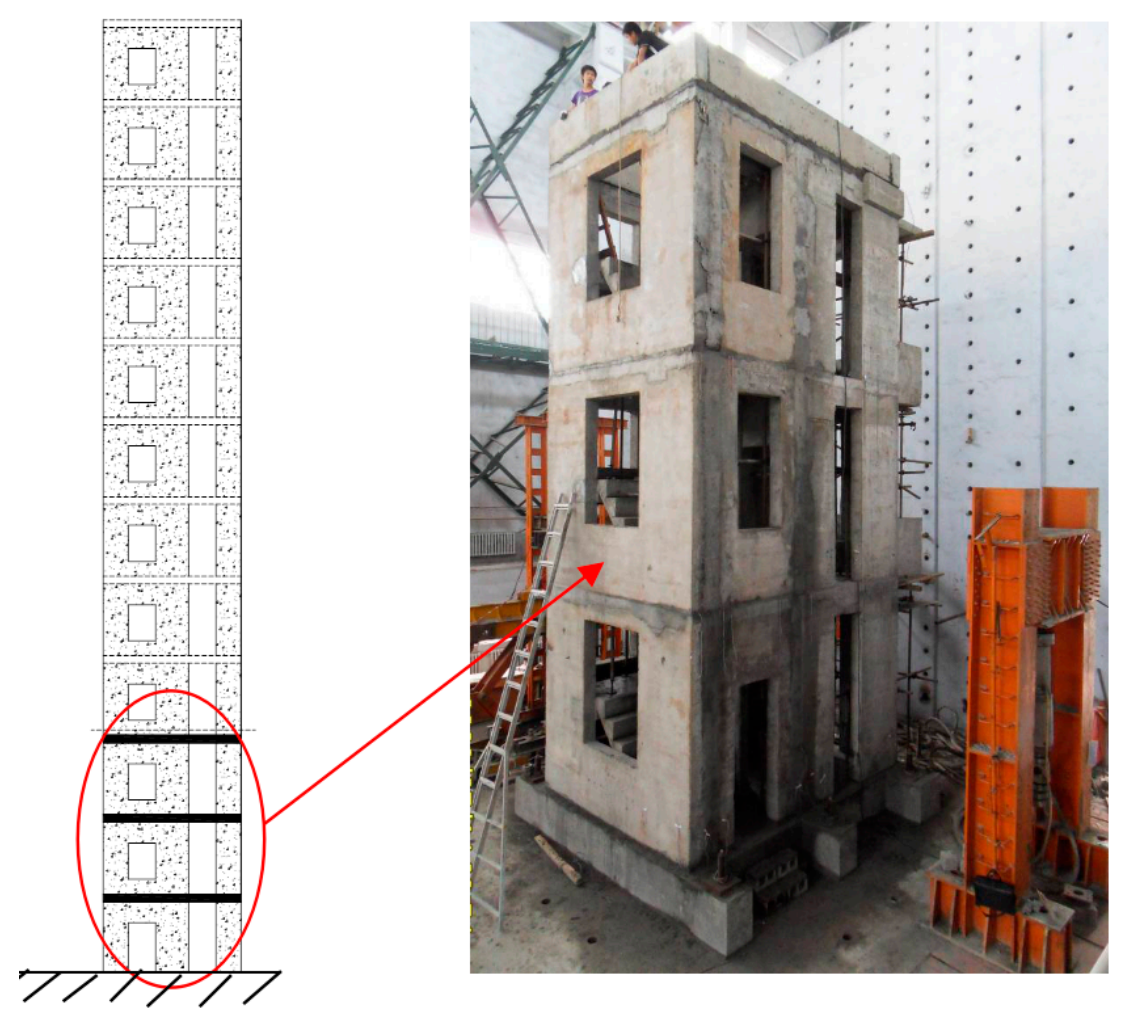

Figure 2. Full-scale three-story precast concrete shear wall substructure model.

Table 1. Calculated parameters for test model.

\begin{tabular}{ccccc}
\hline Floors & $\mathbf{1}$ & $\mathbf{2}$ & $\mathbf{3}$ & $\mathbf{4 ~ 1 2}$ \\
\hline Initial stiffness in positive direction $(\mathrm{kN} / \mathrm{mm})$ & 417 & 295 & 295 & 295 \\
Initial stiffness in negative direction $(\mathrm{kN} / \mathrm{mm})$ & 475 & 359 & 359 & 359 \\
\hline
\end{tabular}


Table 2. Material properties of the concrete.

\begin{tabular}{|c|c|c|c|}
\hline \multirow[t]{2}{*}{ Type } & $\begin{array}{l}\text { Compress Strength of } \\
\text { Concrete }\end{array}$ & $\begin{array}{l}\text { Compress Strength of } \\
\text { Grouting Material }\end{array}$ & $\begin{array}{l}\text { Bending Strength of } \\
\text { Grouting Material }\end{array}$ \\
\hline & $\left(\mathrm{N} / \mathrm{mm}^{2}\right)$ & $\left(\mathrm{N} / \mathrm{mm}^{2}\right)$ & $\left(\mathrm{N} / \mathrm{mm}^{2}\right)$ \\
\hline Precast parts of each floor & 31.6 & - & - \\
\hline Cast-in-place parts of 1st floor & 22.9 & 75.7 & 6.1 \\
\hline Cast-in-place parts of 2 nd floor & 29.5 & 73.8 & 5.9 \\
\hline Cast-in-place parts of 3rd floor & 32.8 & 80.1 & 8.0 \\
\hline
\end{tabular}

Table 3. Material properties of the steel reinforcement.

\begin{tabular}{|c|c|c|}
\hline Diameter & Yield Strength & Limit Strength \\
\hline$(\mathrm{mm})$ & $\left(\mathrm{N} / \mathrm{mm}^{2}\right)$ & $\left(\mathrm{N} / \mathrm{mm}^{2}\right)$ \\
\hline 6 & 353.1 & 504.2 \\
\hline 8 & 290.6 & 433.3 \\
\hline 10 & 308.9 & 429.9 \\
\hline 12 & 386.6 & 560.3 \\
\hline 14 & 340.8 & 483.8 \\
\hline 16 & 283.1 & 443.7 \\
\hline
\end{tabular}

\subsection{Loading Device}

Figure 3 shows the horizontal loading devices which include four hydraulic servo actuators. Only the third floor was loaded by two actuators with the capacity of $\pm 630 \mathrm{kN}$. A same actuator was employed on the middle of the Axes 1 and 2 for the second floor while an actuator with the capacity of $\pm 250 \mathrm{kN}$ was employed for the first floor. The displacement measurement range of all the actuators was $\pm 250 \mathrm{~mm}$. The errors of both force and displacement are the $0.1 \%$ corresponding to the capacity. To prevent the local damage of the beams connecting the actuator, two side beams of the third floor, which located at the end of horizontal loading devices, were partly enlarged to the section of $400 \mathrm{~mm} \times 400 \mathrm{~mm}$. For the bottom two floors, to enable a uniform transfer of horizontal forces to each story, as well as to ensure a tight connection among the beam, the actuator and floor slab, the far end was passed through the wall along the B axis and beam-anchored by high-strength bolts, as shown in Figure 4.

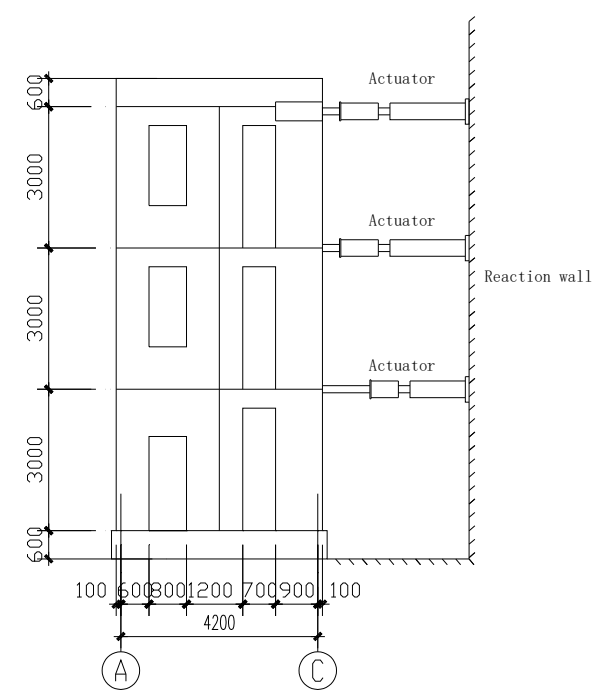

(a)

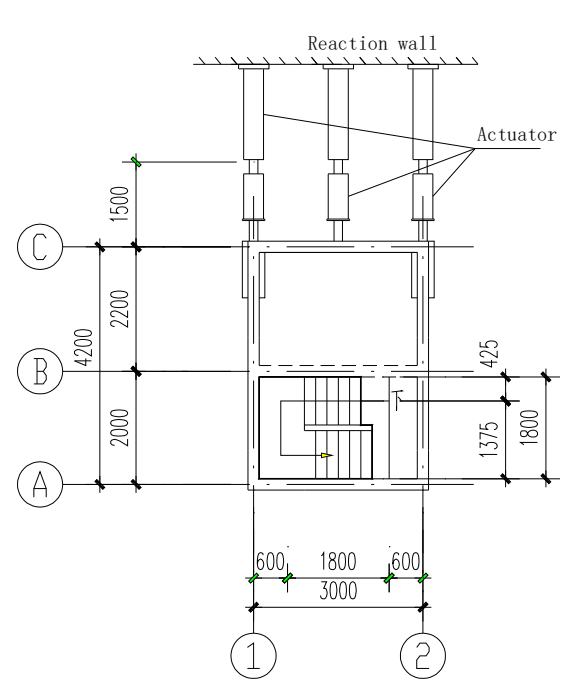

(b)

Figure 3. Planned arrangement of horizontal loading devices for the hybrid simulation testing: (a) elevation; (b) Plan view. 


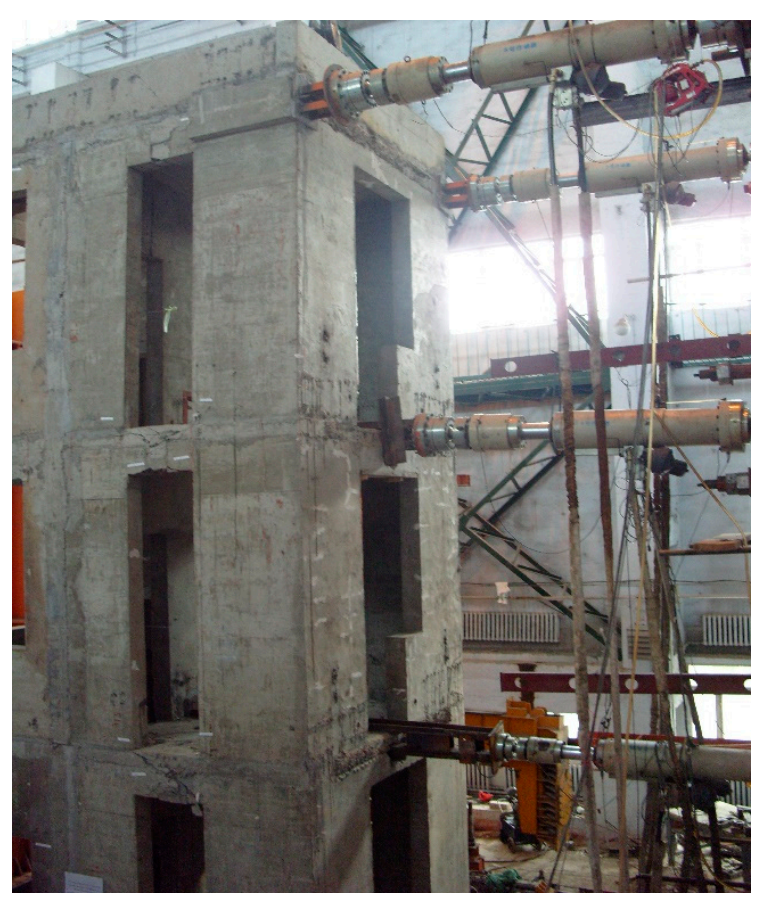

Figure 4. Arrangement of horizontal loading devices.

\subsection{Arrangement of Measuring Points}

During the HS test, a total of ten Linear Variable Differential Transformers (LVDTs) were employed to measure the displacement of the test model. The arrangement of the measuring points is illustrated in Figure 5. Two LVDTs were set up at the top of the foundation beam and each story along Axes 1 and 2, respectively (8 in total); the average value of the pair of LVDTs was used to determine the story drift. Another two LVDTs were arranged at a height of $1 \mathrm{~m}$ and $2 \mathrm{~m}$ above the ground along the Axe 2 .

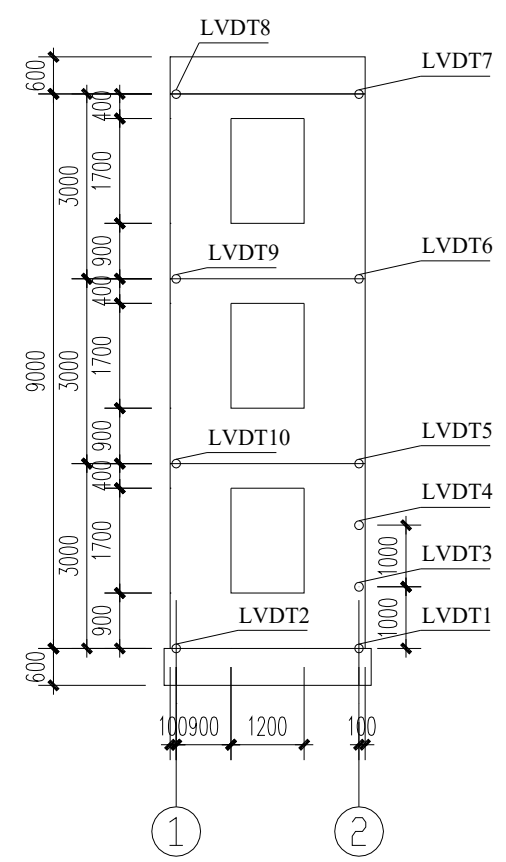

Figure 5. Arrangement of displacement measuring points. 


\section{Parameters of Equivalent Force Control HS Method}

\subsection{Parameter of Numerical Substructure Model}

The EFC method was used for HS [47] with an implicit integration algorithm, during which the mathematical iteration procedure was improved by using a force feedback control. Numerical and experimental results of simple model verified that, as long as the equivalent force controller was properly designed, proposed EFC method was sufficient. This section introduces the detailed test procedure for the aforementioned sophisticated structures with the elastic non-linear numerical substructure.

Considering the asymmetric stiffness in the tension and compression direction caused by the asymmetric structural arrangement of the test model, an asymmetric restoring force model was used in this paper, as shown in Figure 6. In this model, an inflection point exists at the location of the zero displacement for the asymmetric restoring force model of the numerical substructure. Traditionally, the subdivision technique should be used to reduce the computational error at the location of the displacement inflection point. However, the measured error will be inevitably involved because of the increase of the loading step caused by the subdivision technique for the EFC-based HS test. Furthermore, the structural responses were calculated using the feedback from the previous integration steps to gradually approach the exact response at the current step by using the EFC-based HS test. It is difficult to trace back to the previous finished test steps. To this end, no subdivision of integral time interval was taken into account at the location of the displacement inflection point. To make sure the subdivision influence upon the test results, the numerical simulation comparisons between the subdivision and non-subdivision cases were done.

The model parameters of the numerical simulation were taken from the test measurements, as listed in Table 1 . The structural damping was $C=0.05 K$; the restoring force model of each story can be shown in Figure 6. The flowchart of both the subdivision and non-subdivision method is illustrated in Figure 7. The difference between subdivision and non-subdivision method is the step after checking the inflection point of displacement. For the subdivision method, once variations in the inter-story shear force are observed, the subdivision of integral time interval is processed, meaning that the time integration interval is subdivided one step prior to the displacement inflection point. At the same time, the earthquake record was subdivided accordingly. The stiffness at current step is updated and used in the calculations for the remainder of this time interval. For the non-subdivision method, a re-assembly for the stiffness matrices is following in the next step.

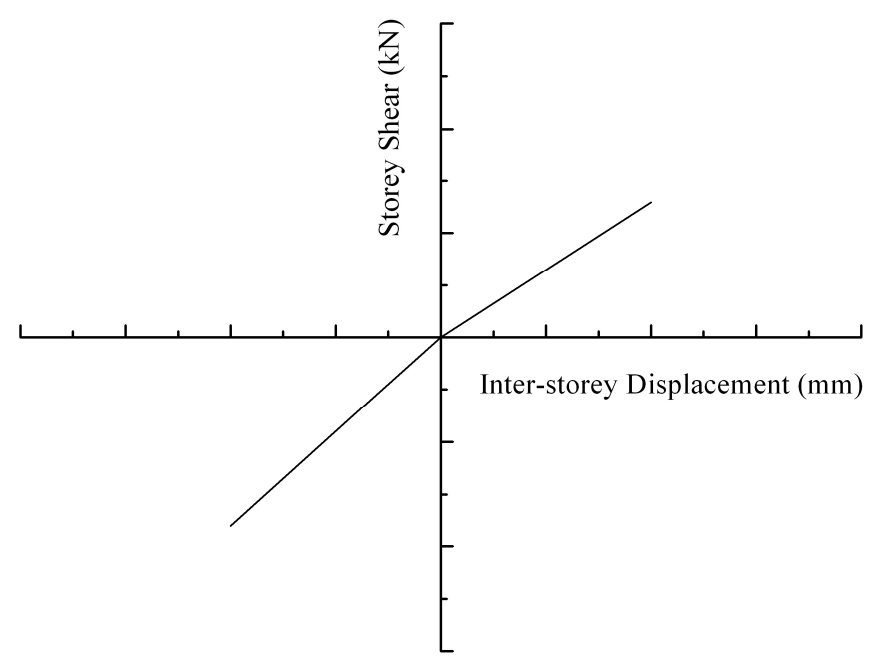

Figure 6. Restoring force model of numerical substructure. 


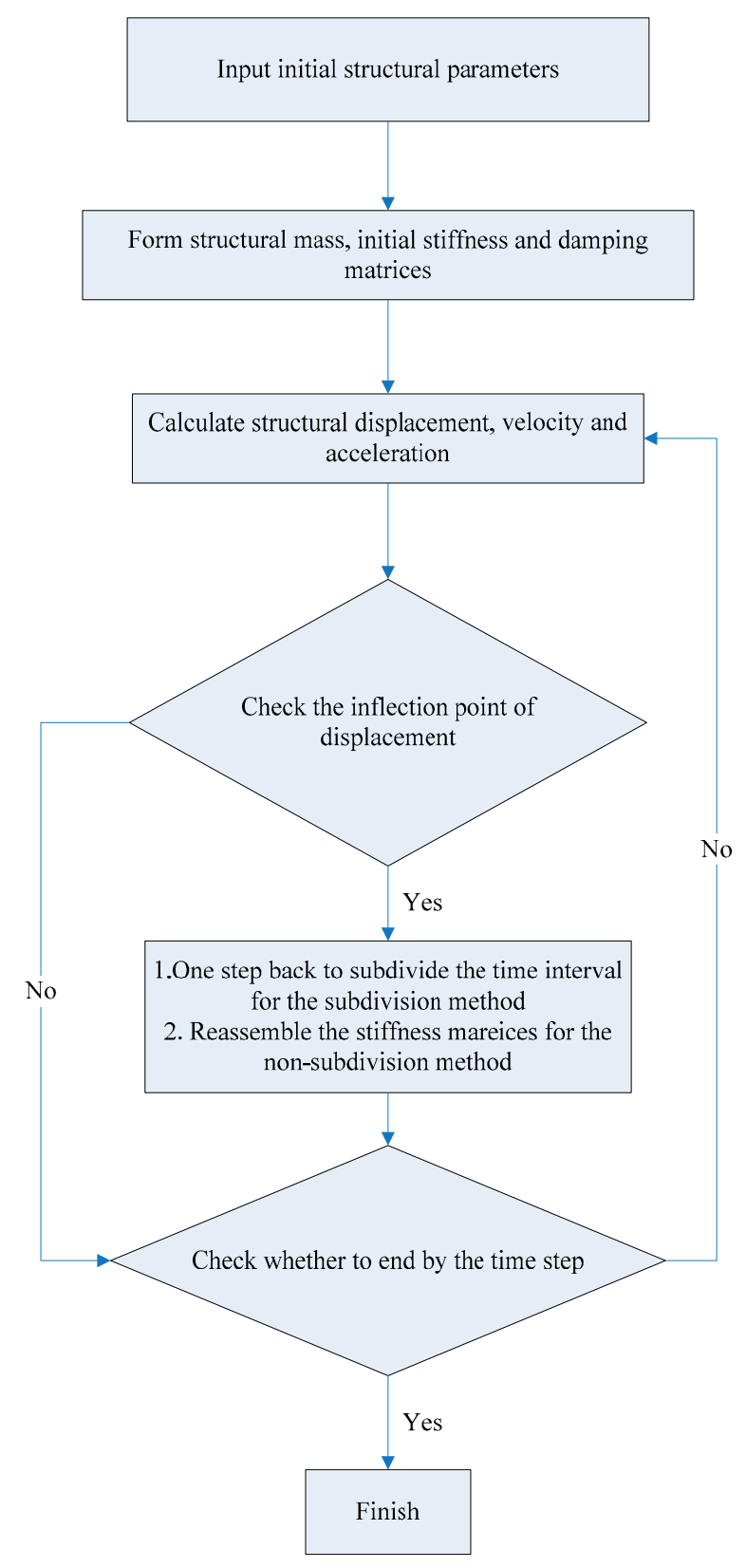

Figure 7. Numerical flowchart using the subdivided integral step and the full integral step.

Figures 8 and 9 show the hysteric curves on the first and second floors under a peak ground acceleration of 110 gal using subdivision and non-subdivision techniques, respectively (other floors are similar to these two floors). Note that both results agree well with the restoring force model as shown in Figure 6. This agreement suggests that the above-mentioned techniques and the corresponding analysis procedures are reliable.

Figure 10 shows the comparisons of the displacement time history curve between the subdivided and non-subdivided integral steps for the first story (the case of the other story is similar and not shown in this research). In order to observe the relationship more clearly, Figure 11 shows the results from $4 \mathrm{~s}$ to $8 \mathrm{~s}$. From the Figures 10 and 11, we can see that both the subdivided and non-subdivided results nearly coincide. Figure 12 shows the time histories of the equivalent force (EF) command and feedback of the first story using the strategy of non-subdivided integral steps (the similar trend in the other story). It is easy to see that the EF feedback tracks the EF command well. In summary, it is feasible that the non-subdivision strategy was used to determine the inflection point of displacement. 


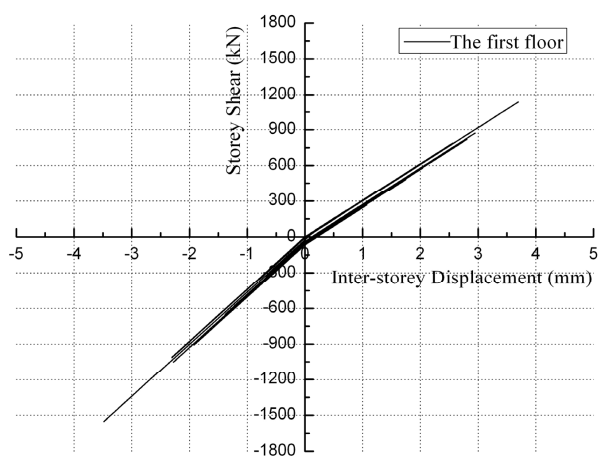

(a)

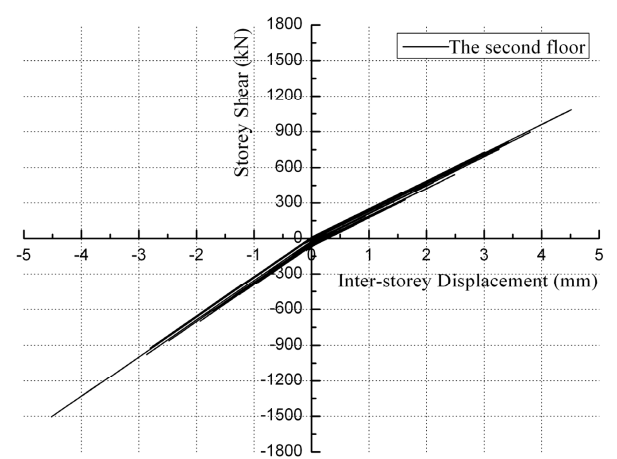

(b)

Figure 8. Relationship of the inter-story restoring force and story drift using the subdivided integral step for (a) the first floor, and (b) the second floor.

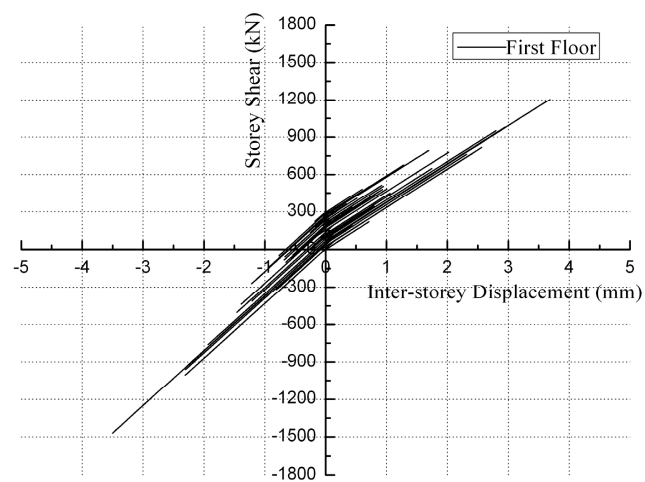

(a)

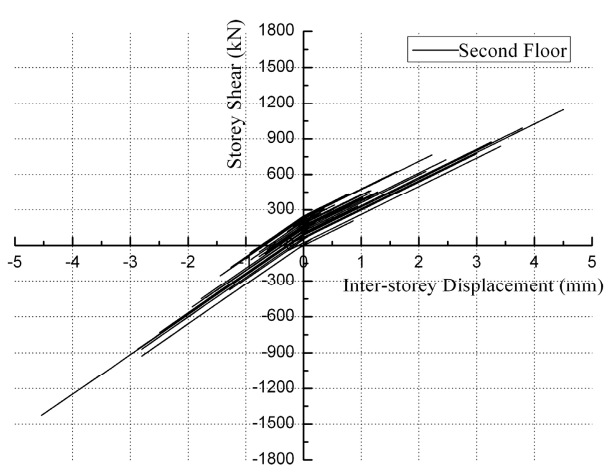

(b)

Figure 9. Relationship of the inter-story restoring force and story drift using the non-subdivided integral step for (a) the first floor, and (b) the second floor.

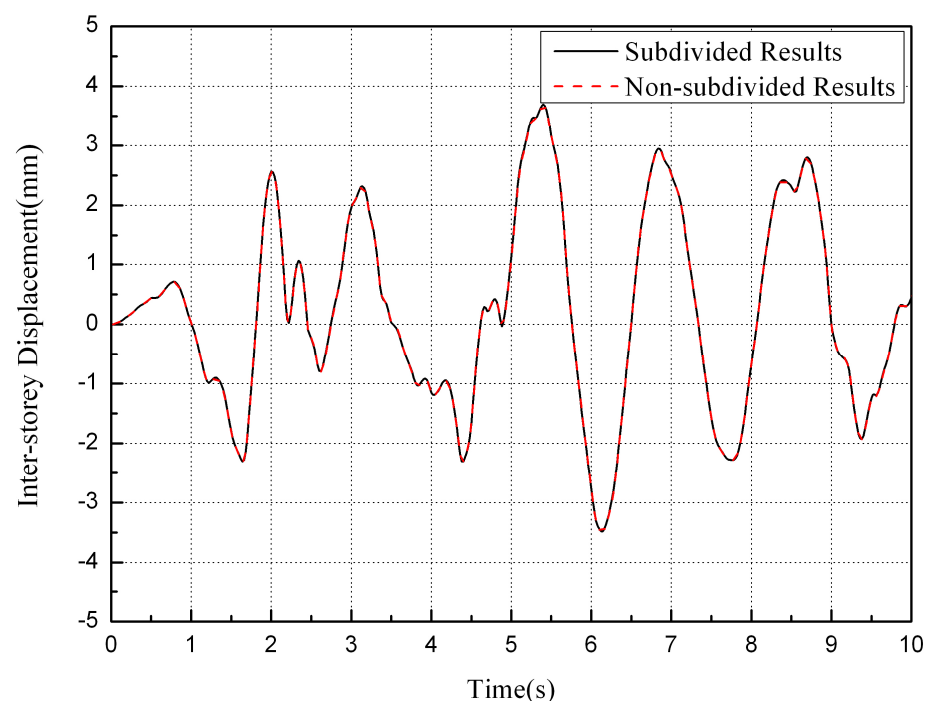

Figure 10. Time history curve of the story drift with different integral steps. 


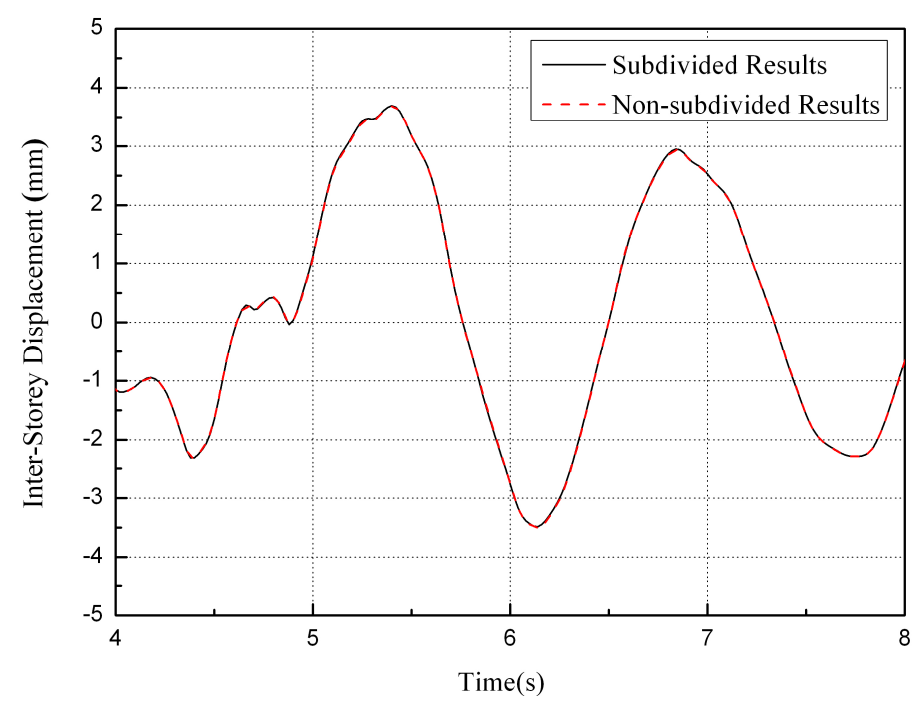

Figure 11. Detailed time history curve of the story drift with different integral steps at $4 \mathrm{~s} \sim 8 \mathrm{~s}$.

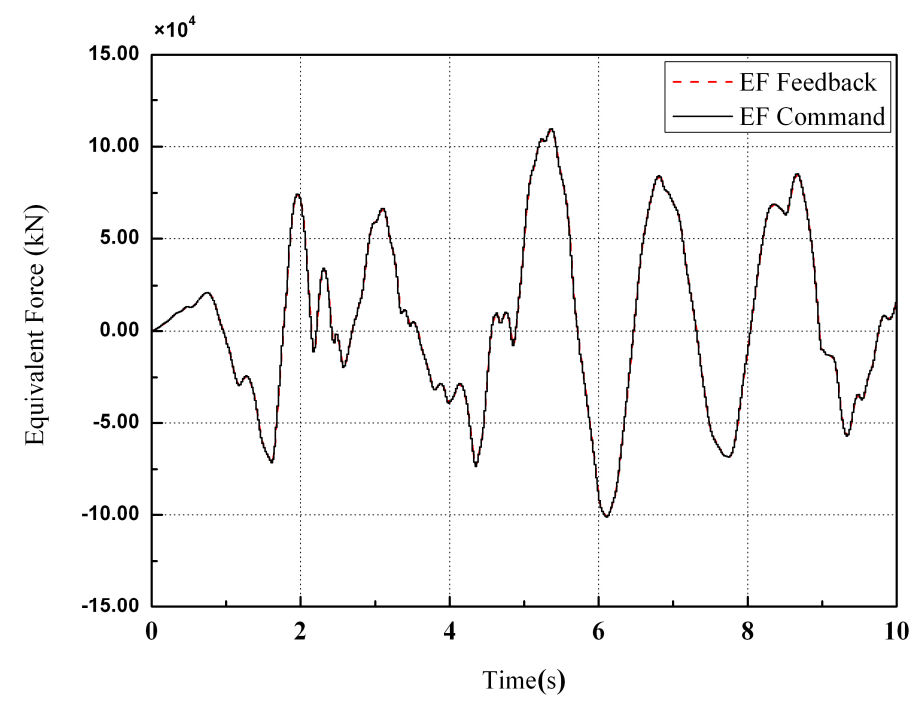

Figure 12. Comparison of the equivalent force (EF) feedback and EF command on the first floor using the non-subdivision method.

\subsection{EFC Parameters}

The previous sections focused on the parameters of the structural restoring force model for the numerical substructure, which was applied with asymmetric tension and compression stiffness, as shown in Figure 6, and the non-subdivision strategy was used to determine the inflection point of displacement. This section presents the determination of the EFC parameters such as force-displacement conversion factor $C_{\mathrm{F}}$, proportional gain $K_{\mathrm{P}}$, and integral gain $\boldsymbol{K}_{\mathrm{I}}$.

Generally, the force-displacement conversion factor $C_{\mathrm{F}}$ can be expressed as

$$
\begin{gathered}
C_{\mathrm{F}}=\left(K_{\mathrm{N}}+K_{\mathrm{PD}}+K_{\mathrm{E}}\right)^{-1} \\
K_{\mathrm{PD}}=\frac{4 M}{\Delta t^{2}}+\frac{2 C}{\Delta t}
\end{gathered}
$$

where $K_{\mathrm{N}}, K_{\mathrm{E}}$ are the stiffness matrices of the numerical and physical substructures, respectively; $K_{\mathrm{PD}}$ is the pseudo-dynamic stiffness; $M, C$ are the mass and damping matrices, respectively, and usually taken to be constant. From Equation (2), given a relatively small time interval $\Delta t$ generally, 
$K_{\mathrm{PD}}$ is considered to be a relatively large component compared to $K_{\mathrm{N}}$ and $K_{\mathrm{E}}$. In the above discussion, the proportional gain $K_{\mathrm{P}}$, and integral gain $\boldsymbol{K}_{\mathrm{I}}$ are the control parameters, while the force-displacement conversion factor $C_{\mathrm{F}}$ calculated by the Equations (1) or (2) is used to transform the equivalent force to the displacement of the model.

Note that it is difficult to calculate the stiffness of the physical substructure due to the test error. For the sake of convenience, the factor $C_{\mathrm{F}}$ is always calculated in terms of the initial stiffness matrices of the numerical and experimental substructures. Then, Equation (1) can be adjusted to

$$
C_{\mathrm{F}}=\left(\boldsymbol{K}_{\mathrm{N}, 0}+K_{\mathrm{PD}}+K_{\mathrm{E}, 0}\right)^{-1}
$$

where $K_{\mathrm{N}, 0}, K_{\mathrm{E}, 0}$ are the initial stiffness matrices of the numerical and experimental substructures, respectively. Because of the asymmetry in the tension and compression stiffness, the following method was used to determine the force-displacement conversion factor $C_{\mathrm{F}}$ : the $K_{\mathrm{N}, 0}$ was used as the practical value while $K_{\mathrm{E}, 0}$ was used as the mean value of the tension and compression stiffness matrices. For the nonlinear test models, the calculation of $C_{\mathrm{F}}$ was based on how the above method impacted the test results. But the effect of the EFC parameters upon the response performance can be adequately reduced through a reasonable design of the EF controller using a self-adaptive control, sliding mode control [48,49], etc. The PI controller was used in this study, as shown in Figure 13. The following section presents a detailed determination of the proportional gain $K_{\mathrm{P}}$ and integral gain $\boldsymbol{K}_{\mathrm{I}}$.

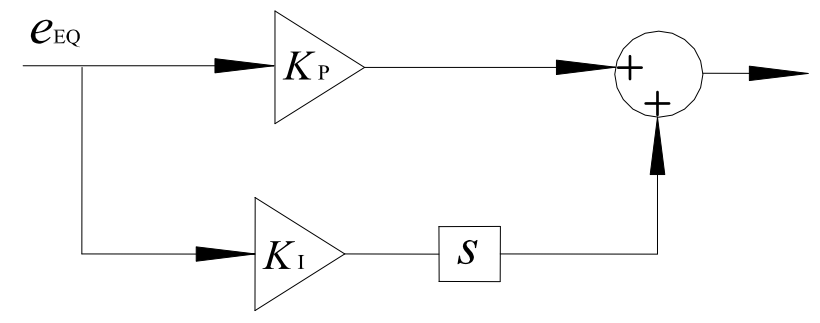

Figure 13. Equivalent force controller.

In order to guarantee that the force-displacement conversion factor $C_{\mathrm{F}}$ in the numerical simulation identically corresponds with the correspondent in the hybrid simulation test, the stiffness of the physical substructure using for the numerical simulation is taken to be the average value of the tested stiffness in the positive and negative directions listed in Table 1. The updated stiffness was listed in Table 4. The elastic nonlinear restoring force model, shown in Figure 6, was adopted for the numerical substructure; at the same time, an elastic linear model was used for the physical substructure.

Table 4. Calculated parameters for test model.

\begin{tabular}{ccccc}
\hline Floors & $\mathbf{1}$ & $\mathbf{2}$ & $\mathbf{3}$ & $\mathbf{4 ~ 1 2}$ \\
\hline Initial stiffness in the positive direction $(\mathrm{kN} / \mathrm{mm})$ & 446 & 327 & 327 & 295 \\
Initial stiffness in the negative direction $(\mathrm{kN} / \mathrm{mm})$ & 446 & 327 & 327 & 359 \\
\hline
\end{tabular}

Figure 14 shows the time histories of the inter-story displacement with a varying $K_{\mathrm{I}}$ of 0.001 , 0.0065 , and 0.01 , and a fixed $K_{\mathrm{P}}$ of 0.05 (only the result of the first floor is shown here, because there were similar results for the other floors). The reference results are obtained using the fourth-order single-step integration method and these can serve as exact solutions (W). Note that with increase of the $K_{\mathrm{I}}$, the results based on the PI controller begin to approach the theoretical solution. This indicates that a moderate increase in $K_{\mathrm{I}}$ can enhance the accuracy of the numerical integration method. However, the comparison between the EF feedback and EF command, shown in Figure 15, suggests that the overshoot (Figure 15c) or undershoot (Figure 15a) phenomenon occurs when $\boldsymbol{K}_{\mathrm{I}}$ when is too large or too small. In other words, a moderate integral gain can enhance both the EF response speed and the 
accuracy of the integration algorithm, while an excessive increment will lead to an overestimation and thereby compromise the results. It is important to point out that increasing the frequency of the EF feedback can relieve some of these accuracy issues. However, this will also dramatically increase the testing duration and potentially lead to a greater rate of test error.

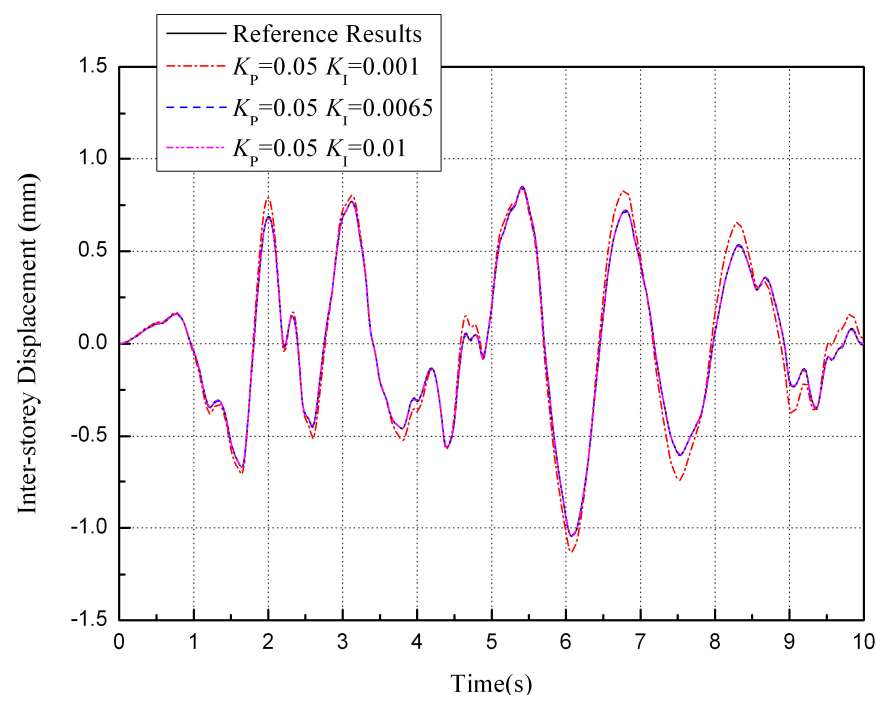

Figure 14. Time history curves of story drift with different integral gains.

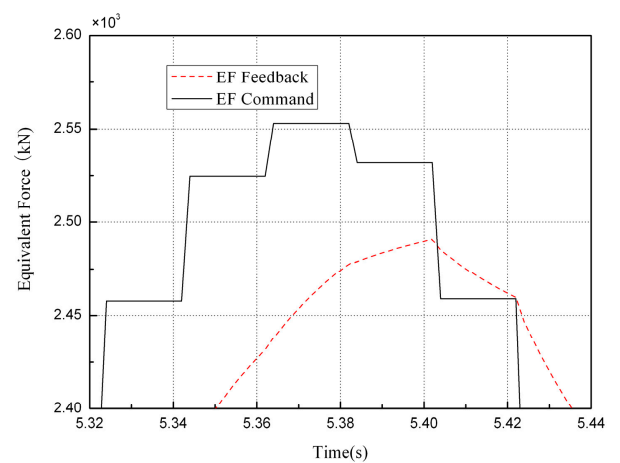

(a)

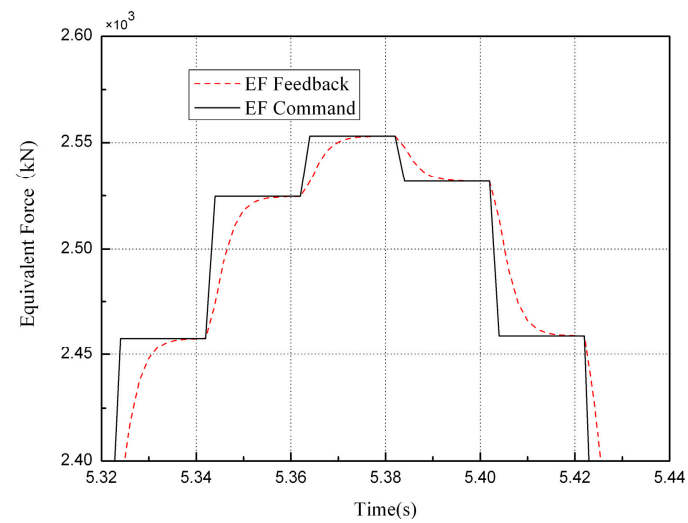

(b)

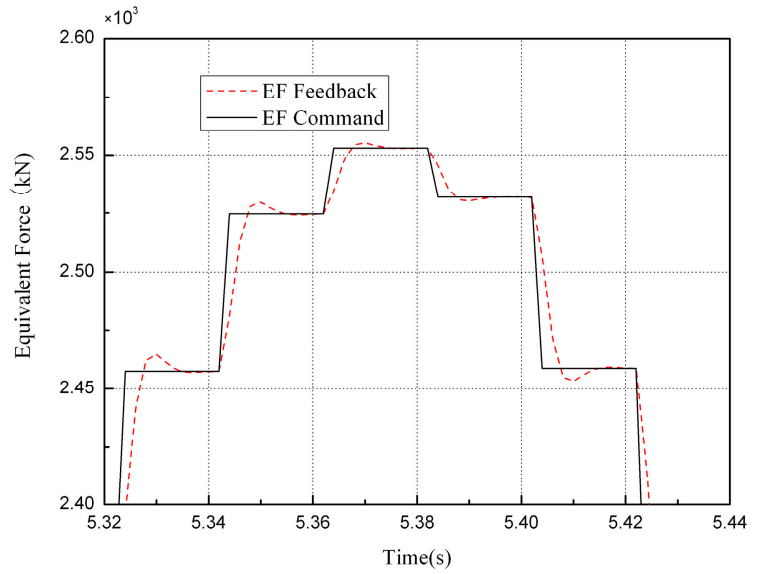

(c)

Figure 15. Comparison of the EF feedback and EF command: (a) $K_{\mathrm{P}}=0.05, K_{\mathrm{I}}=0.001 ;(\mathbf{b}) K_{\mathrm{P}}=0.05$, $K_{\mathrm{I}}=0.0065 ;(\mathbf{c}) K_{\mathrm{P}}=0.05, K_{\mathrm{I}}=0.01$. 
The time histories of the inter-storey displacement with a varying $K_{\mathrm{P}}$ of $0.05,0.01,0.90$ and 1.00 , and a fixed $K_{\mathrm{I}}$ of 0.0065 are shown in Figure 16. As the proportional gain $K_{\mathrm{I}}$ increases, the results from the PI controller deviates from the theoretical results-something similar can be seen in the comparison of the EF feedback and EF command as shown in Figure 17. The excessive actuating displacement may arise due to an excessive proportional gain - which can cause the overshooting and oscillation of the EF feedback that produces unrealistic hysteretic responses. Wu et al. [49] analyzed the EFC method for real-time substructure testing and found that an extensively small proportional gain often led to a time-lag problem of actuator response. This, in turn, introduced negative damping into the numerical substructure model and affected the test results. Increasing the proportional gain can accelerate the EF response, which reduces the time lag in the EF response as well as the negative damping. In contrast, an oversized proportional gain can easily lead to oscillation phenomenon in the EF feedback, and distorted results. In conclusion, the $K_{\mathrm{P}}=0.05, K_{\mathrm{I}}=0.0065$ was adopted in this study.

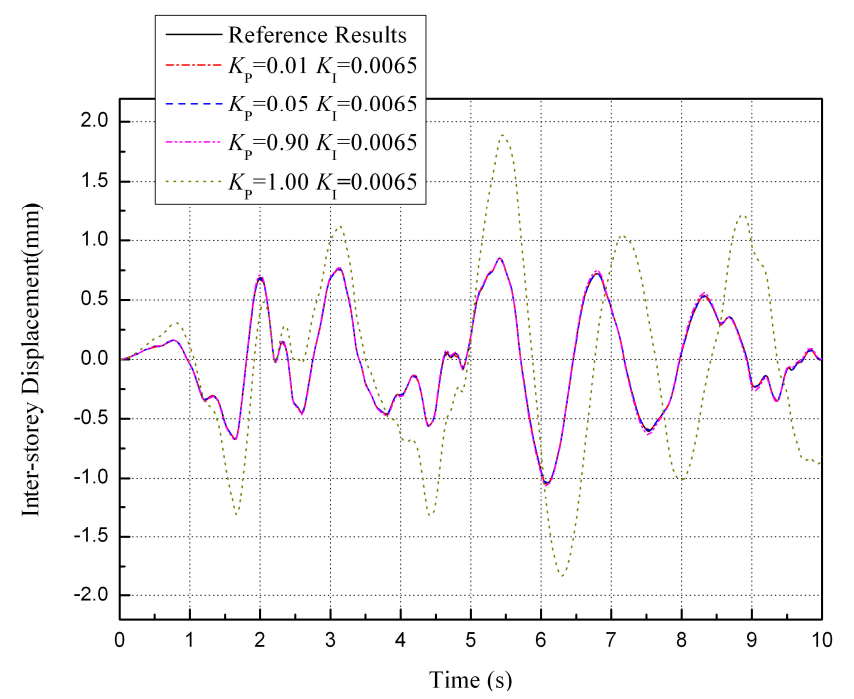

Figure 16. Time history curves of story drift with different proportional gains.

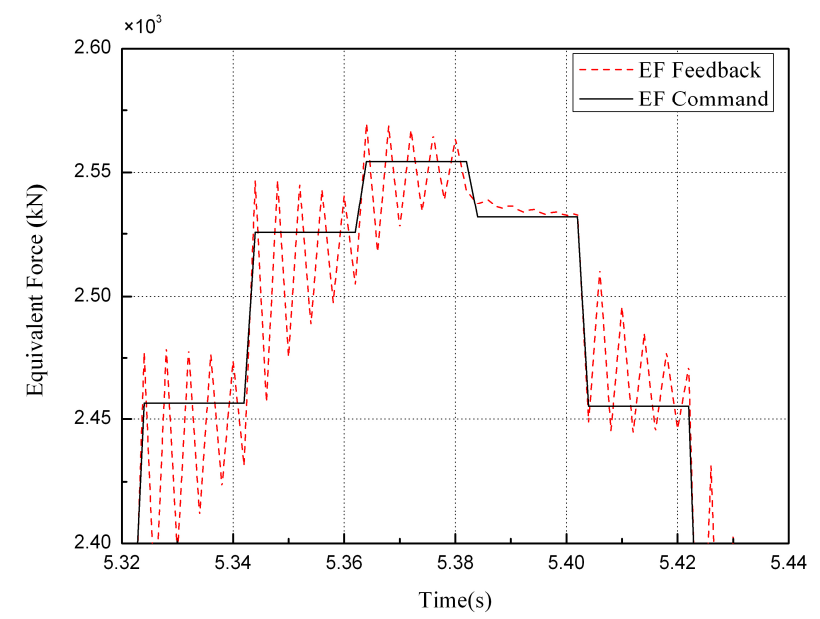

Figure 17. Comparison of the EF feedback and EF command when $K_{\mathrm{P}}=0.9, K_{\mathrm{I}}=0.0065$.

\section{Experimental Validation}

Using the previously mentioned method, a series of hybrid simulation tests were carried out on the test model under the following peak ground accelerations: 35 gal $\rightarrow 70$ gal $\rightarrow 110$ gal $\rightarrow 220$ gal. Figure 18 shows the time histories of the inter-story displacement under different peak ground accelerations. 
Note that in Figure 18d, only the results for the duration of $6.26 \mathrm{~s}$ are present. This was because after the peak displacement, the test model entered the descending stage in the hysteretic curve and the test was artificially terminated when the restoring force recovered to zero at $t=6.26 \mathrm{~s}$. From Figure 18, we can see that the structural responses are controlled by the first mode. As the peak ground acceleration increases, the whole displacement time history becomes increasingly sparse. This suggests that the stiffness of each story, as well as the whole structure, has been degraded. Figures 19 and 20 show the experimental results with a peak ground acceleration of 220 gal. More experimental results will be shown in other study on the structural seismic performance. Figure 19 shows the comparison of the displacement time histories between the EF feedback and EF command. The comparison suggested a good agreement, which indicating that the proposed EFC method performed well. As seen in Figure 20, when the substructure response enters the descending path of the hysteretic curve, the ultimate load of the substructure under the pulling force of the first and second floor is reached. This demonstrates that the EFC can effectively simulate the degrading behavior of the substructure following the ultimate load in the hybrid simulation test.

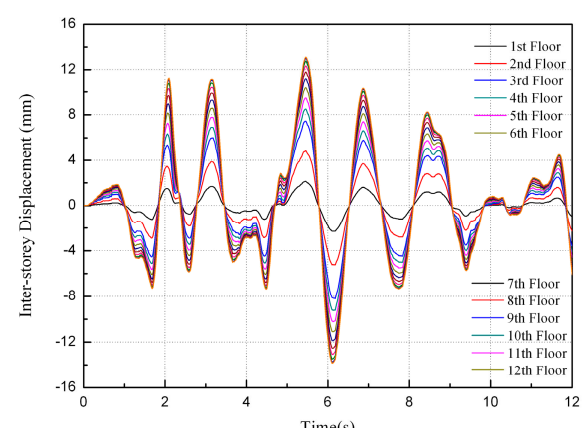

(a)

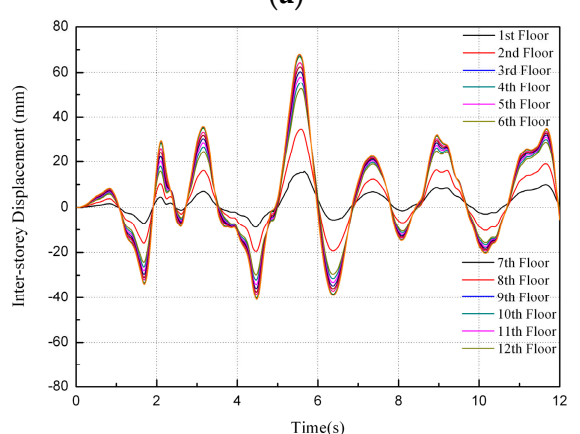

(c)

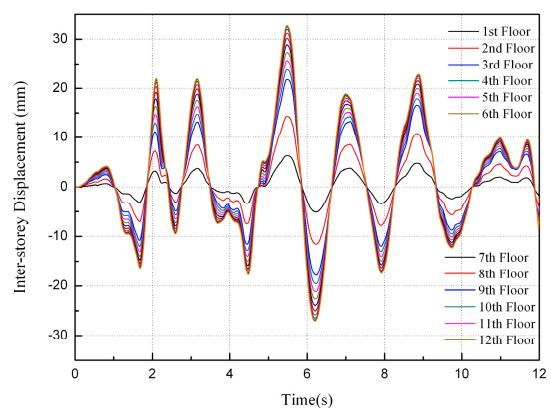

(b)

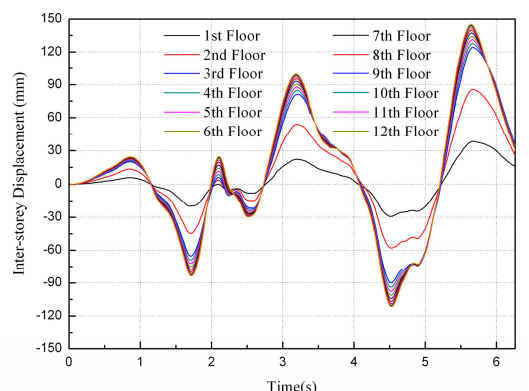

(d)

Figure 18. Time history curves of story drift with different peak accelerations: (a) 35 gal; (b) 70 gal; (c) 110 gal; (d) 220 gal.

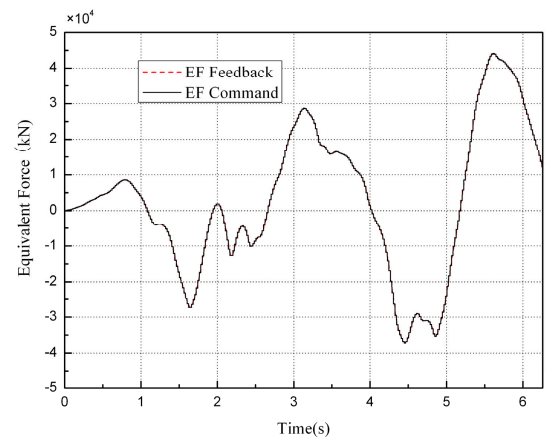

(a)

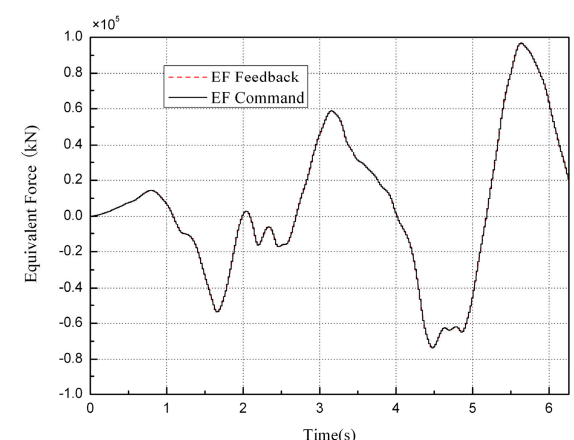

(b)

Figure 19. Cont. 


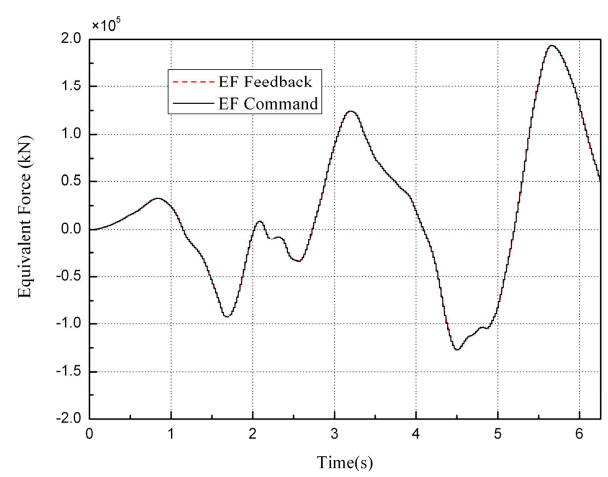

(c)

Figure 19. Comparison of the EF feedback and EF command for (a) the first floor; (b) the second floor; (c) the third floor.

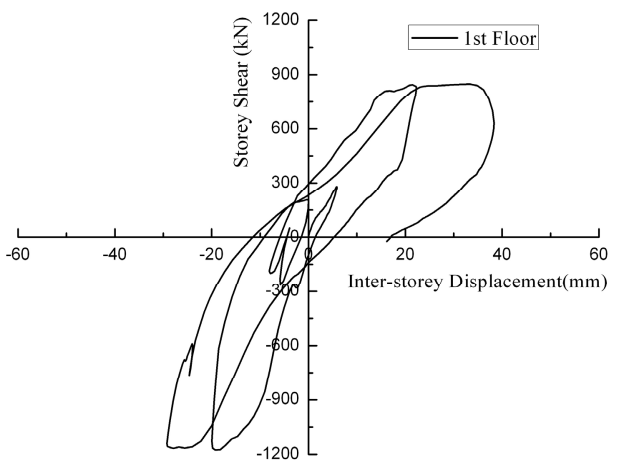

(a)

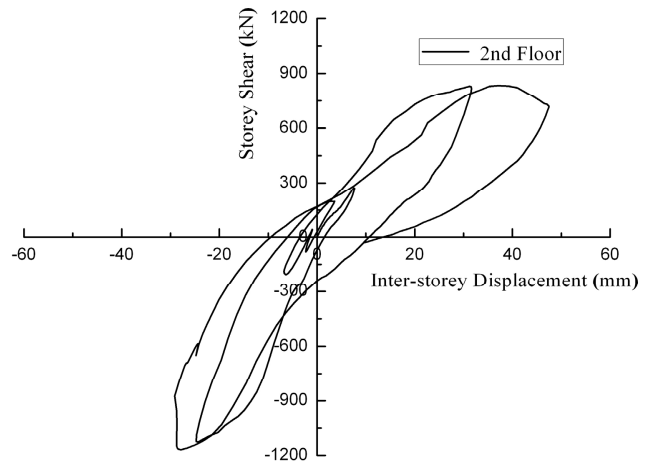

(b)

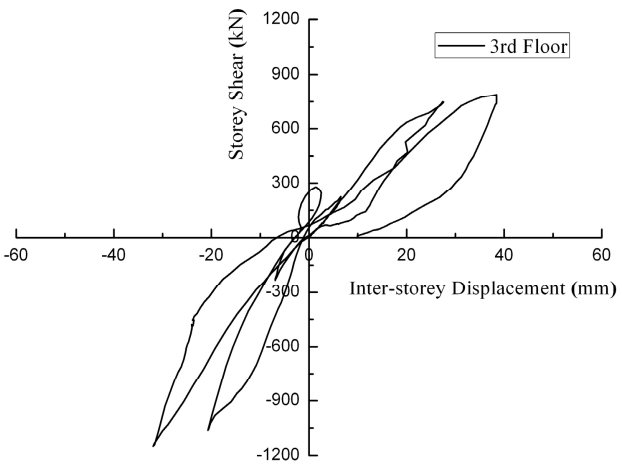

(c)

Figure 20. Relationship of the inter-story restoring force and story drift in the physical substructure under the peak ground acceleration of 220 gal for (a) 1st floor; (b) 2nd floor; (c) 3rd floor.

\section{Conclusions}

This paper presents an application of the EFC for the multy degree of freedom hybrid simulation test combined with the elastic nonlinear numerical substructure model. The following conclusions may be drawn from the results:

(1) The EFC method with implicit integration algorithm was successfully used to the HS test of a twelve-story pre-cast reinforced concrete shear wall structure model. And non-subdivision strategy for the displacement inflection point of numerical substructure is used to easily realize the simulation of the numerical substructure and thus reduce the measured error. The testing results of the descending stage can be conveniently obtained by the EFC based HS method. 
The physical test results show that the EFC based HS method has the good performance in both reliability and accuracy.

(2) A moderate increment in the integral gain can enhance the EF feedback speed as well as the accuracy of the integration. However, an excessively large value may lead to problems of overshooting, and compromise the results. Increasing the proportional gain can accelerate the EF response, reduce the time-leg effect, and decrease damping. Likewise, an excessive value can cause oscillation in the EF feedback while also distorting the results. The displacement control problem can be effectively addressed through reasonable arrangements of the equivalent force controllers.

Acknowledgments: The research is financially supported by the National Science Foundation of China (51678199, $51508495,51161120360)$. The authors also gratefully acknowledge the financial support provided by the China Scholarship Council (CSC) at UIUC (201606125079).

Author Contributions: All authors have made a substantial contribution to this study. Z.C. provided the concept and design of the study. X.Z. wrote and revised the manuscript. H.D.W. and H.J. performed the experiment and collected the data. H.W. and K.W analyzed the experimental data.

Conflicts of Interest: The authors declare no conflict of interest.

\section{References}

1. Hakuno, M.; Shidowara, M.; Haa, T. Dynamic destructive test of a cantilevers beam, Controlled by an analog-computer. Trans. Jpn. Soc. Civ. Eng. 1969, 1969, 1-9. [CrossRef]

2. Chang, S.Y. Explicit pseudo-dynamic algorithm with unconditional stability. J. Eng. Mech. (ASCE) 2002, 128, 935-947. [CrossRef]

3. Chen, C.; Ricles, J.M.; Marullo, T.; Mercan, O. Real-time hybrid testing using the unconditionally stable explicit CR integration algorithm. Earthq. Eng. Struct. Dyn. 2009, 38, 23-44. [CrossRef]

4. Phillips, B.M.; Spencer, B.F. Model-Based Feedforward-Feedback Actuator Control for Real-Time Hybrid Simulation. J. Struct. Eng. 2013, 139, 1205-1214. [CrossRef]

5. Liu, Y.; Goorts, K.; Ashasi-Sorkhabi, A.; Mercan, O.; Narasimhan, S. A state space-based explicit integration method for real-time hybrid simulation. Struct. Control Health Monit. 2016, 23, 641-658. [CrossRef]

6. Kolay, C.; Ricles, J.M.; Marullo, T.M.; Mahvashmohammadi, A.; Sause, R. Implementation and application of the unconditionally stable explicit parametrically dissipative KR- $\alpha$ method for real-time hybrid simulation. Earthq. Eng. Struct. Dyn. 2015, 44, 735-755. [CrossRef]

7. Kolay, C.; Ricles, J.M. Force-Based Frame Element Implementation for Real-Time Hybrid Simulation Using Explicit Direct Integration Algorithms. J. Struct. Eng. 2018, 144, 04017191. [CrossRef]

8. Dimig, J.; Shield, C.; French, C.; Bailey, F.; Clark, A. Effective force testing: A method of seismic simulation for structural testing. J. Struct. Eng. (ASCE) 1999, 125, 1028-1037. [CrossRef]

9. Pan, P.; Nakashima, M.; Tomofuji, H. Online test using displacement-force mixed control. Earthq. Eng. Struct. Dyn. 2005, 34, 869-888. [CrossRef]

10. Nakata, N. Effective force testing using a robust loop shaping controller. Earthq. Eng. Struct. Dyn. 2013, 42, 261-275. [CrossRef]

11. Günay, S.; Mosalam, K.M. Enhancement of real-time hybrid simulation on a shaking table configuration with implementation of an advanced control method. Earthq. Eng. Struct. Dyn. 2015, 44, 657-675. [CrossRef]

12. Ou, G.; Ozdagli, A.I.; Dyke, S.J.; Wu, B. Robust integrated actuator control experimental verification and real-time hybrid simulation implementation. Earthq. Eng. Struct. Dyn. 2015, 44, 441-460. [CrossRef]

13. Yang, T.Y.; Tung, D.P.; Li, Y.; Lin, J.Y.; Li, K.; Guo, W. Theory and implementation of switch-based hybrid simulation technology for earthquake engineering applications. Earthq. Eng. Struct. Dyn. 2017, 46, 2603-2617. [CrossRef]

14. Wu, B.; Ning, X.; Xu, G.; Wang, Z.; Mei, Z.; Yang, G. Online numerical simulation: A hybrid simulation method for in complete boundary conditions. Earthq. Eng. Struct. Dyn. 2017. [CrossRef]

15. Campbell, S.; Stojadinovic, B. A system for simultaneous pseudodynamic testing of multiple substructures. In Proceedings of the 6th U.S. National Conference on Earthquake Engineering, Earthquake Engineering Research Institute, Washington, DC, USA, 31 May-4 June 1998. 
16. Watanabe, E.; Yun, C.B.; Sugiura, K.; Park, D.U.; Nagata, K. On-line interactive testing between KAIST and Kyoto University. In Proceedings of the 14th KKNN Symposiumon Civil Engineering, KKNN Symposium, Kyoto, Japan, 5-7 November 2001.

17. Tsai, K.C.; Yeh, C.C.; Yang, Y.C.; Wang, K.J.; Chen, P.C. Seismic hazard mitigation: Internet-based hybrid testing framework and examples. In Colloquium on Natural Hazard Mitigation: Methods and Applications; Université Pierre et Marie CURIE: Paris, France, 2003.

18. Spencer, B.F.; Carrion, J.E.; Phillips, B.M. Real-time hybrid testing of semi-actively controlled structure with MR damper. In Proceedings of the Second International Conference on Advances in Experimental Structural Engineering, St. Louis, MO, USA, 10-12 June 2009.

19. Kim, S.; Christenson, R.; Phillips, B.; Spencer, B. Geographically distributed real-time hybrid simulation of MR dampers for seismic hazard mitigation. In Proceedings of the 20th Analysis and Computation Specialty Conference, Chicago, IL, USA, 29-31 March 2012; ASCE: Reston, VA, USA, 2012.

20. Li, X.; Ozdagli, A.I.; Dyke, S.J.; Lu, X. Christenson Richard. Development and Verification of Distributed Real-Time Hybrid Simulation Methods. J. Comput. Civ. Eng. 2017, 31, 04017014. [CrossRef]

21. Kwon, O.; Kammula, V. Model updating method for substructure pseudo-dynamic hybrid simulation. Earthq. Eng. Struct. Dyn. 2013, 42, 1971-1984. [CrossRef]

22. Hashemi, M.J.; Masroor, A.; Mosqueda, G. Implementation of online model updating in hybrid simulation. Earthq. Eng. Struct. Dyn. 2014, 43, 395-412. [CrossRef]

23. Wu, B.; Chen, Y.; Xu, G.; Mei, Z.; Pan, T.; Zeng, C. Hybrid simulation of steel frame structures with sectional model updating. Earthq. Eng. Struct. Dyn. 2016, 45, 1251-1269. [CrossRef]

24. Shao, X.; Pang, W.; Griffith, C.; Ziaei, E.; Lindt, J. Development of a hybrid simulation controller for full-scale experimental investigation of seismic retrofits for soft-story woodframe buildings. Earthq. Eng. Struct. Dyn. 2016, 45, 1233-1249. [CrossRef]

25. Chuang, M.; Hsieh, S.; Tsai, K.; Li, C.; Wang, K.; Wu, A. Parameter identification for on-line model updating in hybrid simulations using a gradient-based method. Earthq. Eng. Struct Dyn. 2017. [CrossRef]

26. Mei, Z.; Wu, B.; Bursi, O.S.; Yang, G.; Wang, Z. Hybrid simulation of structural systems with online updating of concrete constitutive law parameters by unscented Kalman filter. Struct. Control Health Monit. 2017, 25, e2069. [CrossRef]

27. Nakashima, M. Development, potential, and limitation of real-time on-line (pseudo-dynamic) testing. Math. Phys. Eng. Sci. 2001, 359, 1851-1867. [CrossRef]

28. Chen, C.; Ricles, J. Improving the inverse compensation method for real-time hybrid simulation through a dual compensation scheme. Earthq. Eng. Struct. Dyn. 2009, 38, 815-832. [CrossRef]

29. Wu, B.; Wang, Z.; Bursi, O. Actuator dynamics compensation based on upper bound delay for real-time hybrid simulation. Earthq. Eng. Struct. Dyn. 2013, 42, 1749-1765. [CrossRef]

30. Gao, X.; Castaneda, N.; Dyke, S. Real-time hybrid simulation: From dynamic system, motion control to experimental error. Earthq. Eng. Struct. Dyn. 2013, 42, 815-832. [CrossRef]

31. Chae, Y.; Kazemibidokhti, K.; Ricles, J. Adaptive time series compensator for delay compensation of servo-hydraulic actuator systems for real-time hybrid simulation. Earthq. Eng. Struct. Dyn. 2013, 42, 1697-1715. [CrossRef]

32. Asai, T.; Chang, C.; Spencer, B. Real-Time Hybrid Simulation of a Smart Base-Isolated Building. J. Eng. Mech. 2015, 141, 04014128. [CrossRef]

33. Wang, J.; Gui, Y.; Zhu, F.; Jin, F.; Zhou, M. Real-time hybrid simulation of multi-story structures installed with tuned liquid damper. Struct. Control Health Monit. 2016, 23, 1015-1031. [CrossRef]

34. Maghareh, A.; Waldbjørn, J.; Dyke, S.; Arun, P.; Ali, I. Adaptive multi-rate interface: Development and experimental verification for real-time hybrid simulation. Earthq. Eng. Struct. Dyn. 2016, 45, 1411-1425. [CrossRef]

35. Zhang, R.; Phillips, B.; Taniguchi, S.; Ikenaga, M.; Ikago, K. Shake table real-time hybrid simulation techniques for the performance evaluation of buildings with inter-story isolation. Struct. Control Health Monit. 2017, 24, e1971. [CrossRef]

36. Zhou, H.; Wagg, D.; Li, M. Equivalent force control combined with adaptive polynomialbased forward prediction for real-time hybrid simulation. Struct. Control Health Monit. 2017, 24, e2018. [CrossRef] 
37. Buckle, I.; Reitherman, R. The Consortium for the George E. Brown, J. Network for Earthquake Engineering Simulation. In Proceedings of the 13th World Conference on Earthquake Engineering, Vancouver, BC, Canada, 1-6 August 2004; Paper No. 4016.

38. Stojadinovic, B.; Mosqueda, G.; Mahin, S.A. Event-driven control system for geographically distributed hybrid simulation. J. Struct. Eng. 2006, 132, 68-77. [CrossRef]

39. Kim, J.K. KOCED collaboratory program. In Proceedings of the ANCER Annual Meeting: Networking of Young Earthquake Engineering Researchers and Professionals, Honolulu, HI, USA, 28-30 July 2004.

40. Ohtani, K.; Ogawa, N.; Katayama, T.; Shibata, H. Project 'E-Defense' (3-D Full-Scale Earthqyake Testing Facility). In Proceedings of the Joint NCREE/JRC Workshop on International Collaboration on Earthquake Disaster Mitigation Research, Taipei, Taiwan, 17-18 November 2003.

41. Takahashi, Y.; Fenves, G. Software framework for distributed experimental-computational simulation of structural systems. Earthq. Eng. Struct. Dyn. 2006, 35, 267-291. [CrossRef]

42. Kwon, O.S.; Elnashai, A.S.; Spencer, B.F. UI-SIMCOR: A global platform for hybrid distributed simulation. In Hybrid Simulation: Theory, Implementation and Applications; CRC Press: Boca Raton, FL, USA, 2008; p. 157.

43. Mahmoud, H.N.; Elnashai, A.S.; Spencer, B.F.; Kwon, O.S.; Bennier, D.J. Hybrid simulation for earthquake response of semirigid partial-strength steel frames. J. Struct. Eng. (U.S.) 2013, 139, 1134-1148. [CrossRef]

44. Murray Justin, A.; Sasani, M. Near-collapse response of existing RC building under severe pulse-type ground motion using hybrid simulation. Earthq. Eng. Struct. Dyn. 2016, 45, 1109-1127. [CrossRef]

45. Abbiati, G.; Bursi, O.S.; Caperan, P.; Sarno, L.D.; Molina, F.J.; Paolacci, F.; Pegon, P. Hybrid simulation of a multi-span RC viaduct with plain bars and sliding bearings. Earthq. Eng. Struct. Dyn. 2015, 44, 2221-2240. [CrossRef]

46. Dong, B.; Sause, R.; Ricles, J.M. Accurate real-time hybrid earthquake simulations on large-scale MDOF steel structure with nonlinear viscous dampers. Earthq. Eng. Struct. Dyn. 2015, 44, 2035-2055. [CrossRef]

47. Wu, B.; Wang, Q.; Shing, P.B.; Ou, J. Equivalent force method for generalized real-time substructure testing with implicit integration. Earthq. Eng. Struct. Dyn. 2007, 36, 1127-1149. [CrossRef]

48. Wagg, D.J.; Stoten, D.P. Substructuring of Dynamical Systems via the Adaptive Minnimal Control Synthesis Algorithm. Earthq. Eng. Struct. Dyn. 2001, 30, 865-877. [CrossRef]

49. Wu, B.; Wang, X.; Wang, Q. Sliding Mode Control of Servohydraulic Testing System and Its Application to Real-time Substructure Testing. In Proceedings of the 4th National Conference on Structural Control, Dalian, China, 11-13 July 2004. 